\title{
Crave de Sarah Kane: aproximación a una dramaturgia performativa
}

\author{
María Lorena Saavedra González \\ Universidad de Playa Ancha \\ maria.saavedra@upla.cl
}

Artículo bajo licencia Creative Commons Atribución 4.0 Internacional (CC BY 4.0) ENVIADO: 2020-03-29 ACEPTADO: 2020-09-13

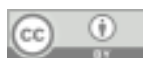

\section{RESUMEN}

La obra de Sarah Kane ha sido considerada como una manifestación dramática que quebró y renovó la escena teatral de los años 90 en Inglaterra, exponiendo la violencia y soledad de su mundo. El presente artículo tiene por objetivo analizar, desde la perspectiva y aproximación de lo que podríamos denominar como una dramaturgia performativa, el texto Crave estrenado el año 1998 y, de este modo, comprender cómo algunas dramaturgias contemporáneas permiten ingresar a otras dimensiones a partir de su lectura, donde lo experiencial y la afectación emergen como aspectos relevantes en los intersticios que existen entre el texto y el lector.

PALABRAS CLAVE

Sarah Kane, dramaturgia, dramaturgia performativa, performatividad, resonancia.

\section{RESUMO}

A obra de Sarah Kane tem sido considerada uma manifestação dramática que quebrou e renovou a cena teatral dos anos 90 na Inglaterra, expondo a violência e a solidão do seu mundo. Este artigo tem por objetivo analisar, a partir da perspectiva e aproximação do que poderíamos chamar de uma dramaturgia performativa, o texto Crave estreado em 1998 e, deste modo, compreender como algumas dramaturgias contemporâneas permitem entrar em outras dimensões a partir da sua leitura, onde 0 experiencial e o afetamento emergem como aspectos relevantes nos interstícios que existem entre o texto e o leitor.

\section{PALABRAS CLAVE}

Sarah Kane, dramaturgia, dramaturgia performativa, performatividade, ressonância.

\section{ABSTRACT}

The work of Sarah Kane has been considered as a dramatic demonstration that broke and renewed England's theatre scene during the 90's by exposing the violence and solitude of her world. The aim of this article is to analyze, from the perspective and approach of which we call a performative dramaturgy, the play Crave, premiered in 1998, in order to understand how some contemporary dramaturgies allow to enter new dimensions after reading them, where the experiential and the emotional involvement emerge as relevant aspects in the interstices between the text and the reader.

\section{KEYWORDS}

Sarah Kane, dramaturgy, performative dramaturgy, performativity, resonance.

\footnotetext{
1 Académica del Departamento de Artes Escénicas - Universidad de Playa Ancha. Doctora $\odot$ en Filosofía mención Estética y Teoría del Arte de la Universidad de Chile. Estudios de posgrado financiados por conicyt: CONICYTPCHA/Doctorado Nacional/2016.

Este artículo es resultado del proyecto de investigación Rescatando nuevas voces: la dramaturgia en Valparaíso durante la democracia plena (2000-2015), folio ART-16/1617, financiado por la Dirección General de Investigación de la Universidad de Playa Ancha.
} 
El devenir del drama clásico occidental ha experimentado quiebres, dislocaciones y desplazamientos observables desde fines del siglo XIX y durante todo el siglo XX como respuesta a un modo y estructura canónica de entender, analizar y representar textos dramáticos. Dichas transformaciones han originado en los investigadores del drama, la búsqueda de nuevos conceptos que permitan observar y comprender las variaciones/modificaciones de la estructura de las obras como también de su lenguaje.

Desde las últimas décadas del siglo pasado, dramaturgias europeas han surgido cual contenedores de su pasado reciente y contingencia de su presente, como respuesta a los cambios que ha experimentado el sujeto en relación al mundo que habita, generándose una dislocación con lo precedente en tanto representación de un tipo de realidad que conlleva nuevas maneras de presentarse, portanto, evidencia modificaciones en diversos aspectos como, por ejemplo, la noción de fábula y personaje.

Diversos estudios asociados al drama, donde encontramos trabajos de Peter Szondi, Jean-Pierre Sarrazac, Jean-Pierre Ryngaert, Robert Abirached, Víctor Viviescas, hablan de la crisis de la representación que se retrata, por consiguiente, en la crisis del diálogo enunciado en voz de un desdibujado personaje que ya no responde a formas y estilos enmarcados al realismo/naturalismo decimonónico. En correlación con los cambios en la dramaturgia, también han surgido diferentes denominaciones en torno a la palabra dramaturgia "llegando a convertirse en un campo disperso de actividades cuya relación con las estructuras teatrales de la representación es más que nunca inherente y sin embargo cada vez más fantasmal". (Heahtfield, 2011:102)

Transformaciones en la dramaturgia occidental se pueden observar en autores desde finales del siglo $X I X^{2}$, pero podríamos afirmar que los cambios más radicales surgen con la aparición de las vanguardias europeas en el periodo entre guerras y, más exponencialmente, producto de las consecuencias de la segunda guerra mundial. En este sentido, y pensando en los procesos de crisis político/sociales que ha atravesado Europa y gran parte de occidente, hoy la dramaturgia exige nuevas maneras de representar lo real, en tanto las formas normativas de la escritura dramática ya no son suficientes para pensar y recrear el mundo actual.

Asimismo, no solo estos hechos bélicos, sino también los posteriores ${ }^{3}$, como también los grandes cambios sociales han modificado sustancialmente el rol del ser humano en la sociedad, sus preocupaciones, sus dolores, sus angustias se ven expuestos en dramaturgias que muestran el vaciamiento, el sin sentido y la violencia que ha emanado de las tierras que habitan. En este sentido es importante destacar que tales deslizamientos anteriormente mencionados, han producido formas dramáticas cuyas fisonomías han dejado de exponer las problemáticas intersubje-

2 Entre los más destacados están Ibsen, Chéjov, Strindberg, Maeterlinck, Hauptmann.

3 Luego del término de la Segunda Guerra Mundial, el mundo ha sido partícipe de una cantidad importante de guerras y genocidios que han ocasionado masacres y conflictos que asoman hasta el día de hoy, entre ellas encontramos: Guerra del Golfo (1990-1991), Guerra de Bosnia (1992-1995), Guerra Chechena (1994-1996), Genocidio de Ruanda (1994), I y II Guerra del Congo (1996-2003), Guerra de Kosovo (1999) entre otras. 
tivas tradicionales en tanto lo dialógico fue la representación vital del drama social, a situaciones intrasubjetivas en las cuales el ser humano se tiene a sí mismo como tarea.

La apertura a nuevas formas que superen la dramática estaría vinculada a la necesidad de buscar nuevas formas de representación del mundo y nuevos lenguajes para interpretarlo. Y esta exigencia, a su vez, estaría vinculada a los cambios culturales y sociopolíticos que se han producido en el mundo occidental en las últimas décadas. Desde la caída del muro de Berlín hasta la crisis institucional en la Unión Europea aún en curso, la conformación del espacio geográfico, político, social, identidario ha ido mutando rápida y radicalmente. Es la mismísima fabula de la Europa la que, en los últimos años, está pasando por una crisis. (Carnevali, 2017:25-26)

La fisura social de lo interpersonal como metáfora del conflicto de vida dio lugar a la condición escindida de la vida cotidiana, originando una escritura de intersticios humanos interiores y separados de las relaciones sociales tradicionales, en donde la soledad surge como un apéndice de la vida contemporánea que se evidencia a través de una dimensión textual subvertida; en otras palabras, podemos apelar a que "la homogeneidad de otras épocas en cuanto al predominio de un método o estilo, dio paso a una exultante multiplicidad de formas expresivas, estilos diferentes y métodos que competían por reflejar, producir o descubrir mejor las contradicciones y comportamientos humanos" (Hormigón, 2011: 28). Tal comportamiento y su particular estilo de evidenciarlo a través de su dimensión textual, es el que abordaremos en la obra Crave de la dramaturga británica Sarah Kane.

Sarah Kane es una autora británica que nació en la ciudad de Essex en 1971 y murió tempranamente por ahorcamiento a la edad de 28 años en la ciudad de Londres. Kane manifestó desde sus primeros años interés por las artes y las letras, estudiando Arte Dramático en la Universidad de Bristol. Si bien, su labor artística transitó por diversas áreas como la actuación, la dirección y la dramaturgia, es esta última por la que ha sido ampliamente conocida y estudiada. Considerada como una de las dramaturgas más destacada de su época, ha llevado a escena sus propias obsesiones y fantasmas a partir de personajes inadaptados y cargados de una violencia verbal, corporal y simbólica. En su corta carrera escribió cinco obras: Blasted (1995), Phaedra's love (1996), Cleansed (1997), Crave (1998), Psychosis 4.48 (1998/99) y un guion para cortometraje titulado Skin (1997). Entre los motivos dramáticos que cruzan transversalmente sus textos encontramos la violencia, el sexo, la soledad, la desesperación, el sinsentido, la muerte, la deshumanización, entre otros, dando cuenta de una generación de jóvenes dramaturgos/as que fueron herederos de los más grandes crímenes y cambios que experimentó el mundo.

La violencia y sexualidad desenfadada son algunos de los rasgos recurrentes y decisivos que caracterizan la obra de Kane. Ellos constituyen el soporte estético e ideológico que aglutino a diversos dramaturgos jóvenes de la década de los noventa incluida ella y los llevó a una propuesta teatral claramente diferenciada de la tradición dramática anterior. (Brncic, 2006: 27)
Estos rasgos estéticos e ideológicos es lo que Carolina Brncic denomina, en relación a la obra de Kane, como espectáculo del dolor ${ }^{4}$ donde su fuerte componente confrontacional la llevo a ser considerada dentro del grupo denominado por Aleks Sierz como In yer face Theatre.

Crave, estrenada en agosto de 1998, unos meses antes de su muerte, presenta un lenguaje complejo y, por ende, difícil de comprender en primera instancia, pues estamos siendo lectores/as de una particular escritura dramática que toma distancia de normas tradicionales, en tanto lenguaje estructurado, no apelando de manera directa a lo racional, sino que afecta e interpela los sentidos, la percepción y la emoción. Estas características, junto con otras que serán descritas en el presente escrito, es lo que nos permitirá pensarla y definirla como una dramaturgia performativa. ${ }^{5}$
4 "Sarah Kane y el espectáculo del dolor" Revista Chilena de Literatura, noviembre 2006, número 69. https://scielo.conicyt.cl/scielo. php?script=sci_arttext\&pid=S0718-22952006000200002

5 Para el presente trabajo abordaremos el término de performatividad y performativo el que ha sido desarrollado ampliamente a partir del hecho escénico, sin embargo, propondremos una traslación de tales aspectos desplegados en la praxis teatral para situarlos en la obra dramática. 


\section{PERFORMATIVIDAD/DRAMATURGIA PERFORMATIVA}

Para comprender qué será entendido como dramaturgia performativa, se vuelve necesario hacer una panorámica general de lo que se ha considerado como performatividad. Dicho concepto fue descrito, no aún con el nombre de performatividad, sino con el nombre de expresiones performativas, por el filósofo J. L. Austin, “quien hacia mediados de los años cincuenta propuso estudiar aquellos "actos del habla"6 que afectan el estado de las cosas en el momento mismo de su ejecución" (Prieto, 2009:16), es decir, aquellas expresiones del lenguaje y de la comunicación no verbal "que ejercen alguna acción transformadora" (Prieto, 2009:16).

Ahora bien, la denominación específica de performatividad y lo performativo surge y se utiliza para hablar de ciertas manifestaciones artísticas originadas desde las artes visuales, asociada a lo que hoy conocemos como performance art? . Esta hacía referencia a la emergencia de escapar de los límites canónicos que asumían las artes visuales buscando otros modos y soportes de creación. En el área de los estudios teatrales o de la performance, es, entre otras, la teórica alemana Erika Fischer-Lichte $(2011)^{8}$ quien ha desarrollado ampliamente el concepto, y si bien ceñido más al fenómeno teatral, nos parece interesante las definiciones y características en torno a lo que entiende como performatividad. La autora toma distancia de la hegemonía textual para acercarse a análisis a partir de los actos realizados por el performer como elemento material de la teatralidad. Al interior de aquel acto, lo performativo borra las fronteras entre la idea de un creador/a-autor/a frente a una recepción pasiva, constituyéndose un nuevo lugar de contagio energético: el espacio performativo. Este espacio es un lugar intermedio "un espacio en continua mudanza, en el que la espacialidad tiene su origen en el movimiento y la percepción de actores y espectadores" (Fischer-Lichte, 2011: 233) que para el caso del presente escrito será observable entre la autora y el lector/a pues potencia una atmósfera particular.

Continuando con el recorrido, podemos observar cómo el concepto se ha ampliado a diversas áreas y tal como asevera Diana Taylor “el performance, pues, es una práctica y una epistemología, una forma de comprender el mundo y un lente metodológico" (2012: 31), licencia que nos permite, por la amplitud de su aplicación y mirada, aventurarnos y trasladarla a una obra dramática, específicamente, Crave de Sarah Kane.

Para comenzar, diremos que la performatividad no es un concepto estable o que se defina en un tópico inaltera-

Sin embargo, esta definición de Austin que refería sólo a los actos del habla y, con el pasar de los años, se trasladaría a otros ámbitos.

Cabe destacar que el Performance art fue una práctica artística nacida de la conjunción de diversas disciplinas, considerándose a movimiento Dadá como su origen. Así, su aparición en Europa y Estados Unidos surge de prácticas y disciplinas variadas como la danza, la poesía, las artes visuales y el teatro. Su aparición emerge como reacción y respuesta a las normas establecidas para las artes interpelando al mundo y la crisis en la cual se encontraba. Desde este contexto experimentan con sus propias materialidades, cuestionando y rompiendo los márgenes establecidos y generando nuevas y variadas propuestas de creación que serían antecedentes para las nuevas generaciones de artistas.

Para mayor conocimiento sugiero la lectura Estética de lo performativo (2011). ble, ya que se reconoce justamente en su procesualidad, por lo tanto, es móvil y cambiante, razón por la cual nos atrevemos a trasladarla al plano dramatúrgico. Entendido desde este punto de vista, podemos pensar lo performativo, en el interior de la dramaturgia, como un recurso que también escapa a los límites que tenía el lenguaje y su uso en un texto dramático tradicional, nos referimos específicamente al legado que han desarrollado autores como Aristóteles, Hegel, Lessing, Szondi. De este modo, una dramaturgia performativa podría ser estudiada como un giro a un tipo de textualidad enunciada en obras clásicas y modernas centradas en el logos a partir de la fábula, en tanto estructura lógica y coherente, es decir, entorno a la idea del bello animal 9 o de drama absoluto ${ }^{10}$, para dar paso a textos donde el énfasis está dado en su capacidad de generar una resonancia ${ }^{11}$ en el lector/a. Una resonancia directa a través del uso del lenguaje, del juego y la performatividad de la palabra para repercutir no solo a nivel del intelecto sino, sobre todo, en el cuerpo. Un texto donde acontece una dimensión distinta a un análisis de tipo semiótico (que responde a una lectura sígnica del lector/receptor) a una dramaturgia activa, toda vez que construye una movilidad de emociones y sensaciones a medida que los sucesos o estados van emergiendo/provocando/progresando. Es decir, una dramaturgia configurada no en una acción o un personaje, sino en una pulsión inscrita en un teatro íntimo, de estados, de emociones y no (aunque no excluyente) de la racionalidad. Más aún, una dramaturgia donde se podría exhibir la experiencia del autor/a, es decir, asoma su presencia como sujeto, generando un acto transformador y transgresor de formas y estilos a través de marcas en su lenguaje y su capacidad de concebir imágenes, en contraposición a la idea de una ficcionalización. Una dramaturgia en la que se ha dialogizado un nuevo lenguaje dramático/ performativo para dar paso a voces textuales que alcanzan dimensiones de afección para poner en un juego relacional al destinatario/a.

En esta línea, el libro Teatro Posdramático (2013) y los análisis allí desarrollados por Lehmann también pueden tener consideraciones y vínculos con lo expuesto, toda vez que muchos de los conceptos abordados dicen relación con el plano de la percepción, del predominio de lo sensorial y atmosférico por sobre lo racional. Este fenómeno representacional es una respuesta a textualidades contemporáneas en donde los medios de comunicación y las nuevas tecnologías han modificado los sistemas de creación y recepción. Lehmann no niega el drama, solo que lo sitúa y considera como un elemento más dentro de la experiencia escénica restándole primacía y acercándose así a la propuesta de Artaud, quien ha sido considerado como inspiración y referente, a partir de su perspectiva de la crueldad, a la obra de Kane. Artaud dirá que no somos libres y lo que se debe hacer es derribar las ataduras y volver a la esencia del arte teatral, para ello es indispensable matar al Dios hegemónico inserto en lo que Derrida denominó la Escena

En La poética, Aristóteles alude al "bello animal” para referirse a las características que debe poseer la fábula, en tanto, una totalidad ordenada, coherente y lógica.

10 El drama absoluto es una noción ampliamente desarrollada por Peter Szondi. Esta es entendida como una entidad primigenia y autónoma del autor y del espectador, es decir se configura como un texto que posee un mundo cerrado. Para mayor desarrollo se sugiere la lectura Teoría del drama moderno (1880-1950)

11 Entenderemos resonancia como aquel acto de proyectar una determinada sensación o emoción de manera periódica en otro cuerpo. 
Teológica. Solo así se podrá volver al origen terminado con la idea imitativa que ha tenido el arte desde Aristóteles.

En consecuencia, diremos que una dramaturgia performativa se inscribe más en un tipo de texto donde surge una exposición radical de un sujeto enunciador que evidencia un proceso reflexivo, de autoconocimiento y de producción, abierto a la interpretación del lector/a, un texto que va desde un cuerpo emocional que contagia a través de la resonancia.

\section{CRAVE}

Crave, traducido como Ansia, es la penúltima obra que escribió Sarah Kane, estrenada por primera vez en 1998 por la compañía Paines Plough en el Traverse Theatre de la ciudad de Edimburgo. La obra ha sido considerada como un antecedente dramatúrgico de lo que sería 4.48 Psicosis, siendo ambos textos los más complejos y diferentes a sus anteriores producciones. Con Crave se experimenta una estilización en el lenguaje, alejándose de una connotación de violencia directa observable en obras como Blasted $^{12}$, para dar paso a un lenguaje más poético donde temas como el amor, la muerte, el suicidio, la violación, la anorexia, la drogadicción, entre otros, son expuestos a través de una corriente del pensamiento desdoblada en cuatro voces. En él se visualiza un tipo de escritura en donde, si bien se aprecian cuatro personajes ${ }^{13} \mathrm{~A}, \mathrm{~B}, \mathrm{C}$ y $\mathrm{M}$ con sus respectivos textos y con aparentes diálogos, tales aspectos no solo son travestidos sino también complejizados. La lectura y análisis que se ha realizado respecto a la obra no ha sido unívoca, por el contrario, se ha pensado y analizado desde diversos aspectos; condición que ya evidencia una cualidad de la performatividad al entenderse esta en una relación medial, en el acto de la lectura, donde no existen códigos, mensajes o un discurso claro en la voz de estos cuatro personajes, sino que al finalizar la lectura se puede o no entender una totalidad.

La obra, desplegada a través de lo que concebimos como una gran escena, no relata una historia que se pudiese considerar bien estructurada, lógica y coherente situada en un espacio-tiempo determinado. Desde esta afirmación no surge explícitamente una cronología lineal, no se observa una relación causal, como tampoco se podrían aseverar de manera tajante los temas o motivos que de la lectura se desprenden; sin embargo, nos atrevemos a considerar que el amor, el dolor, la soledad y la muerte son los grandes motivos desde donde emergen otros, por tanto, la interpretación de tales aspectos queda en manos del lector/a a partir de lo expuesto por la autora. En relación a dicho alcance podríamos adscribir a lo que plantea Sarrazac respecto a que "el autor, al estar presente en su obra bajo el aspecto de sujeto rapsódico ${ }^{14}$, opera una reconfiguración del diálogo lateral confinado en el escenario entre los personajes; se amplía considerablemente haciéndose heterogéneo y multidimensional” (Sarrazac, 2015: 89). Desde

12 Blasted (1995), traducido como Devastados, habla de la devastación del hombre, de lo arruinado del amor, de lo deshecho de las relaciones sexuales y de la ruina del Estado, a partir de la violencia y la desesperación al límite de sus personajes. Los diálogos despliegan personajes que develan un sujeto (i)racional, cuya psicología se encuentra perturbada, revelando dimensiones humanas insospechadas dentro de un mundo aparentemente humanizado. La devastación de sus vidas y de su entorno develan la angustia de vivir en soledad y donde la muerte circunda por todos los rincones, pues son habitantes de un espacio movido por la fatalidad, por la acción de fuerzas oscuras e irracionales que los llevan a acciones como agredir físicamente, a violar, a matar o ser capaces de practicar antropofagia.

13 Si bien se menciona la palabra personaje, esta será modificada al avanzar el escrito en tanto se describan características de la obra.

14 Jean-Pierre Sarrazac define al Sujeto Rapsódico a la presencia del autor/ra presente como un sujeto Clivé, es decir, como un sujeto que está más allá de lo dramático y/o lo épico, que puede aparecer como personaje que es parte de la acción, pero también como testigo, lo que provoca una modificación/trasgresión del diálogo dramático, lo que él denominará diálogo mediatizado. En obras como Crave y 4.48 Psicosis se hace casi imposible no pensar en la presencia del autor y su contexto. 
aquello surge la idea de un diálogo mediatizado, que es entendido como

un diálogo que cose (rhaptein en griego antiguo significa 'coser') modos poéticos diferentes, e incluso refractarios entre sí (modos lírico, épico, dramático, argumentativo). El rapsoda es ese cosedor-descosedor. Un nuevo "reparto de voces» se instaura allí donde la voz (que no se expresa más que a través de las acotaciones, que se inmiscuye en las intervenciones de los personajes) y el gesto del rapsoda (el de la composición, la fragmentación, el montaje reivindicado) se intercalan entre las voces y los gestos de los personajes. (Sarrazac, 2011: 25)

Desde aquel diálogo, lo que exponen los personajes bien puede ser entendido como pensamientos inscritos en un lugar indeterminado donde no representan acciones de manera tradicional, pues estaría asomándose el sujeto rapsódico a través de la performatividad de la palabra, emergiendo estados emocionales que aportan lo experiencial, la vivencia, la construcción de un acontecimiento que se termina, finalmente, por completar con el lector/a y/o espectador/a. De este modo, la performatividad no está sólo en la esfera del texto, sino también en los intersticios que existen entre éste y quien lee como puesta en juego de afecciones que tienen como destino la estimulación de una lectura provocativa y reaccionaria, evitando aquel proceso identificatorio tradicional de leer un texto dramático. Es justamente este espacio liminal donde se configura uno de los aspectos más relevantes de este tipo de dramaturgias, que no son pensadas y articuladas de modo fijo y claro, sino que son móviles y permeables a interpretaciones variadas y cómplices, lo que sin duda convierte a Crave en un acontecimiento ${ }^{15}$ que emerge en el ejercicio mismo de aquella lectura más relacional.

Para esclarecer nuestra aproximación de Crave como una dramaturgia performativa, abordaremos algunos aspectos que consideramos significativos para catalogarla como tal.

El primero de ellos se refiere a la relación con la ausencia de una acción y conflicto explícito, propio de una dramaturgia clásica y/o moderna. Si consideramos a Crave un ejemplo de la crisis del drama, resulta evidente su fisura con el modelo precedente, en tanto la obra no posee una fábula estructurada, tampoco límites espacio/temporales más o menos fijos, no existe la concepción de personajes y su tridimensionalidad, tampoco unidad de acción donde se reconozcan objetivos claros. Lo que acontece entonces es una gran escena donde no hay acción, sino un "cuerpo que siente, que siente nostalgia, siente enfermedades, (...) y dolor...sobre todo dolor", (Cornago, 2011: 7) a través de instantes discontinuos y/o desunidos surgiendo el sujeto rapsódico que se fusiona y mezcla con una ficción dramática. Lo que tenemos entonces es un teatro de estados donde no es posible una interpretación, lo que revela la cualidad de una textualidad contestataria en cuanto energía que produ-

15 Es importante esclarecer que para este trabajo se entiende acontecimiento en el ejercicio de la lectura y, por ende, en los pensamientos e imágenes que se realizan al momento de leer la obra, específicamente en el plano de la medialidad entre autor y lector. ce, provoca y proyecta, apareciendo una posible exégesis a partir del ensamblaje de sus diferentes estados.

El lenguaje que se despliega desde una polifonía de voces, (en lo que finalmente ha devenido el personaje), pone de manifiesto una ruptura con la acción y la idea de conflicto enmarcada en personajes con fuerzas y objetivos opuestos, por lo tanto, surge una dramaturgia performati$v a$ a través de la utilización de las palabras que permiten una multiplicidad de códigos y lecturas que propone una situación dinámica y aglutinadora, apareciendo un nuevo agenciamiento de la materialidad de la lengua a través de un cuerpo que emite una voz, una voz que es una corriente de pensamiento en shock; en consecuencia, la idea de la enunciación de la palabra y la instancia de pensar, de recordar y traer al presente crea una relación dinámica, performativa entre la autora y el espacio de la lectura.

A: Una nenita estaba paralizada por las cada vez más frecuentes y violentas discusiones de sus padres. A veces se pasaba horas de pie inmóvil en el baño, simplemente porque era ahí donde estaba cuando comenzaba la pelea. Finalmente, en momentos de calma, agarraba botellas de leche de la heladera o de la entrada y las iba dejando en lugares donde pensaba que podía quedar atrapada la próxima vez. Sus padres no lograban comprender por qué encontraban botellas de leche cortada en todos los rincones de la casa. (Kane, 2005: 41)

Más que una acción estamos ante el proceso de una situación/acontecimiento, que se dice, que se enuncia, que se recuerda y se declara como acto en sí mismo. Estas afirmaciones nos llevan a pensar en un teatro íntimo, donde "lo íntimo se define como lo superlativo del "adentro", el interior del interior, el nivel más profundo del yo" (Sarrazac, 2013: 111) emergiendo el inconsciente en voz de A, B, C y $M$. De este modo, la noción de lo íntimo y la falta de acción hace presente la idea de estatismo en contraposición a la de acción. Crave se configura como una obra donde la "categoría de situación sustituye a la de la acción, el movimiento dramático toma su fuente de una tensión entre la inmovilidad física de los personajes y su movilidad psíquica" (Sarrazac, 2013: 90). Ahora bien, la acción que determinamos como no pertinente en Crave, también podría ser explicada por la ausencia de personaje, entendido al interior del drama clásico y moderno, pues, "se encuentra, en primer lugar, despojado de todas las complicidades con la vida psicológica y social que le habían sido impuestas desde Diderot" (Abirached, 1994: 380), para dar paso a un tipo de personaje que "ha perdido características físicas tanto como referencias sociales; raramente tiene un pasado o una historia, menos aún proyectos futuros o de porvenir identificables" (Sarrazac, 2013: 167). Por ende, en Crave la crisis del personaje está en relación con la crisis del diálogo y esta con la crisis del conflicto, no existiendo conexión con un personaje que evidencie en su hablar características que puedan configurarlo de manera realista; más aún: ha perdido hasta su nombre. Por lo tanto, la idea de personaje se desvanece y asoma una performatividad del cuerpo despersonalizado, de un cuerpo desdoblado en cuatro voces. Lo que apreciamos en Crave son voces dichas a través de $A, B, C$ y $M$, que en su interacción componen una polifonía de estados. Su desarrollo -en el proceso de lectura a través de las palabras, de un hablar sin pausa, de 
la repetición, de la fragmentación- hace emerger dichos estados que generan incluso una procesualidad emotiva al límite, cuya percepción en el lector/a, lleva a proyectar imágenes y atmósferas que van mutando al avanzar el texto como si fuera un efecto sinestésico espiralizado a modo de un transcurso beckettiano permanente.

B: Me duele la espalda.

C: Me duele la cabeza.

A: Me duele el corazón. (Kane, 2005: 23)

No es posible comprender una progresión fluida y no existe un desarrollo de estas cuatro voces, más bien se puede pensar en el desdoblamiento de un solo ser en cuatro fragmentos a través de un reparto de voces que conllevan todos los comportamientos para la puesta en juego de la (in) consciencia. Podríamos hablar de una voz performativa que a medida que avanza la lectura se va proyectando y cambiando, provocando un flujo de estados desde un ritmo interior que la propia textualidad impone. Esta voz performativa es algo así como una puesta en abismo de un pensamiento al límite, que va ocasionando un intercambio de saberes, conocimientos, estados emocionales a través de un prominente carácter procesual (dinámico) de la situación/acontecimiento:

Como se ha visto, en el teatro de Kane el lenguaje invoca y evoca el cuerpo, y el espacio acústico creado por las voces y el ritmo de las réplicas siempre es invitado a dialogar con el espacio físico. Aun así, hay aquí una voluntad patente, por parte de la autora, de que el drama se conciba también como unidad musical, y es precisamente esta unidad la que ahora sustituye de alguna manera la unidad de la fabula. (Carnevali, 2017: 243)

Dicha voz performativa se sitúa en el espacio de la sensación y de lo inmaterial en tanto irrumpe toda una experiencia emocional que nace desde el lenguaje, esto es, un acto de comunicación no centrado en el diálogo, en su representación; sino que desde la fluidez del texto, de la emergencia del estado en esas voces polifónicas, evidenciando lo efímero de la existencia humana, se logra observar el proceso de estas voces como un continuum perceptual y de complicidad, porque el acto performativo surge en el espacio de la medialidad $^{16}$. Crave es un texto que presenta e incorpora nuevos modos de percibirlo, cargado de imágenes, sensaciones, situaciones, que finalmente promueve la posibilidad de entenderlo como una

16 Erika Fischer-Lichte desarrolla la medialidad como una cualidad especial que acontece en la representación teatral a diferencia de otras manifestaciones artísticas, debido a la presencia de cuerpos (actores/actrices y espectadores/as) en un espacio físico concreto y un tiempo determinado. Por ende, la producción y recepción de lo visto y oído acontecería de manera inmediata. Para el desarrollo del presente escrito y dadas las características que se desplegarán en él en torno a una dramaturgia performativa, la medialidad será entendida como aquel espacio entre la voz de la autora (personajes) y el lector/a, propiciando percepciones, emociones y afectaciones. dramaturgia performativa. Una dramaturgia que no se relaciona con lo material, sino con lo experiencial, con lo afectivo, con el conflicto íntimo proyectado hacia situaciones límites posibles de un sujeto particular, pero que también puede ser entendido como conflictos universales. Es decir, un contagio emanado desde la preponderancia de voces, de un conjunto de trazos textuales que poseen identidades diversas o, en otras palabras, donde "el dramaturgo reúne siluetas bosquejadas rápidamente en el colectivo de voces" (Ryngaert, Sermon, 2015: 62).

Desde estas observaciones, difícilmente Crave puede ser entendida como un diálogo o conversación, pues el uso performativo de la lengua a través de una polifonía de voces sugiere un acontecer de un conflicto íntimo. Pero tampoco este "conflicto" remite al modo como ha sido expuesto y analizado en la dramaturgia clásica y/o moderna; aquí lo íntimo surge desde la performancia de un cuerpo que siente y conflictúa con sus otros yo, con su historia y memoria personal a través de la interacción de voces que genera una situación/ acontecimiento desde la emergencia de la densidad y acumulación del juego de las palabras a partir del ritmo. Es el ritmo, por tanto, un aspecto crucial y central en un texto de esta naturaleza, pues genera un todo, un conjunto y una gran imagen que es el resultado de una obra descentrada en aspectos tales como la acción, personaje, conflicto, diálogo. Hablaremos entonces de una situación/acontecimiento que surge en el momento de la lectura donde lo que se aprecia aparece en la medialidad entre la palabra de la autora en voz de $A, B, C$ y $M$ y el lector/a; es decir, una situación hace desaparecer una acción en pos de una dramaturgia que presenta estados que se configura a través de la interacción entre las cuatro letras y el lector/a, mejor aún, un contagio que genera dicha resonancia antes mencionada. 


\section{MEDIALIDAD/CONTAGIO/RESONANCIA}

Otra de las características relevantes que observamos e identificamos para señalar a Crave como una dramaturgia performativa sería su capacidad de generar estados en la esfera de la medialidad. Ello porque la obra puede ser entendida como la presencia de un cuerpo y una voz más que como representación de un personaje y una historia, experiencia develada en la medialidad más que mera comunicación y entrega de información, un acontecimiento experiencial más que significación. En fin, una energía presente desplegada desde la palabra performativa, de un cuerpo y una mente en un aquí y ahora. Fischer-Lichte desarrolla el concepto de medialidad en el ámbito de la escenificación, no obstante, las características que extiende también se reconocen en el intersticio entre la obra y su lectura, donde la importancia del texto radica en el acto transformador de ella, en un espacio y tiempo dedicado a la interacción y la performatividad de la palabra, situada más en el cuerpo de quien lee y no en el ejercicio racional de la comprensión. No olvidemos que en forma general el texto dramático según Anne Ubersfeld y Roman Ingarden, posee una característica dual, es decir es un texto para ser leído, pero también, y quizás, sobre todo, para ser oído, de ahí su performancia en la acción del decir y hacer ante un otro, en este caso de las imágenes que se proyectan y construyen a medida que se lee. Es en esta medialidad donde surge un contagio emanado de un cuerpo escindido que siente y que expresa a través del ritmo e interacción de voces, que desnudan y develan un sentir ya que tiene como resultado no un fin absoluto ni cerrado, sino un progresivo estar en un presente que genera, sin duda, una resonancia que no pasa indiferente: siempre evoca, provoca, perturba. Finalmente, acontece en el cuerpo del lector/a. Asimismo, no todo es una construcción lógica, un flujo de sentido, no todo es imagen y palabra significante, pues posee un carácter dinámico no unidireccional, no representa una realidad, sino más bien una densidad de un presente que surge en el momento mismo de su interacción.

El contagio sería esa cualidad de transmitir, de interactuar y provocar sentimientos, percepciones y/o actitudes corporales a través del lenguaje. En Crave este contagio se potencia en la forma como está escrito el texto y, por ende, por la lectura y su manera de llegar o resonar en el lector/a. Los modos de ingresar están dados por la materialidad del significante verbal, por la utilización y disposición de las palabras, por su morfología, por la sintaxis, por el ritmo, la sonoridad del texto leído, es decir, por la alteración de todos estos elementos que provocan un dislocamiento de la estructura de la lengua, lo que incita la confusión, la indeterminación de lo que se quiere entregar, pues no es un mensaje ni un discurso, sino más bien, es un estado, por ende un desplazamiento de lo racional a lo emocional.
C: Odio estas palabras que me mantienen viva. Odio estas palabras que no me dejan morir.

B: Expresando mi dolor sin aliviar mi dolor

C: Ja ja ja

B: Je je je

C: Ji ji ji

C: Para mí ser yo es inaceptable.

A: Estás perdiendo tus facultades mentales ante mis propios ojos.

M: Me deslizó en silencio hasta el descontrol.

B: Dejame. (sic)

M: Ir. (Kane, 2005: 41)

Desde estas afirmaciones, una dramaturgia performativa provocaría un cambio en la experiencia de la recepción a través del juego activo del texto, de este modo, desarrolla un tipo de textualidad distinta a la forma dramática hegemónica que marcó pautas y directrices por siglos, para dar paso a un texto dramático donde el juego y la experimentación de las formas materiales y sensoriales se ven trasvertidas y cobran protagonismo a través de la resonancia. La resonancia actúa como un verbo activo que provoca cambio y movilidad de los estados del receptor/a a partir de la magnitud que tuvo la palabra, es decir, una resonancia nacida desde la estructura y disposición de las voces hablantes a través de ritmos, cadencias e imágenes, pero no de una palabra fija, sino del juego del devenir de la palabra en emoción y movilidad del cuerpo escucha.

En resumen, este contagio y su resonancia nacen de un sujeto escindido tanto de la morfología como de la sintaxis; tanto del plano lingüístico como también del enclaustramiento de sus emociones. Surge de este modo una pulsión de la palabra proyectada en imágenes que se perciben a través de los sentidos donde A, B, C y M muestran un cuerpo y una psiquis a ratos fragmentada, en otros unidos, pero que a posteriori dejan en evidencia una interdependencia, configurando un tipo de personaje dislocado de un eje central. Sarah Kane pareciera manifestar con Crave que representar la violencia, la muerte y el dolor de manera concreta, a través de acciones como las presentes en Blasted, ya no resonaría del mismo modo que antes, pues el mundo está plagado de imágenes de violencia y de muerte que se ven en diversos medios de comunicación sin ningún filtro. Ante esta saturación de imágenes, el lenguaje queda como el único espacio para evidenciar la crisis, donde el lenguaje es más que sangre, de este modo, surge como una performatividad que construye un acontecimiento: un texto performativo que complejiza la capacidad de representación del mundo. 


\section{A MODO DE CONCLUSIóN}

Enmarcar bajo parámetros claros y definidos dramaturgias como Crave presentes en un mundo de permanente cuestionamiento, de una crisis constante del sujeto y su representación, es una manera de presentar un quiebre con las formas clásicas de entender la dramaturgia y el lenguaje teatral. Escapa a un tipo de texto demasiado cercano a la lectura de signos y estructuras convencionales y, por ende, alejando de la experiencia de los sentidos. Crave propone una forma otra de acercarse a la dramaturgia. Aquella que no apela al intelecto y por lo tanto a la capacidad de entender semióticamente un mensaje o un discurso en términos lingüísticos, acercándose más a lo que denominados una dramaturgia puesta en acción frente al lector/a. Crave da cuenta de un giro o cambio de paradigma que se viene constatando en diversos autores/as contemporáneos, evidenciando un desplazamiento de la hegemonía de la palabra, entendida bajo parámetros de una estructura coherente de la comunicación. En esta lógica, muchas otras obras presentan aspectos que hemos desarrollado aquí, no obstante, el énfasis está dado en la performatividad de un cuerpo y una conciencia múltiple y doliente que se manifiesta en una dramaturgia que pareciera apoyarse más en los estados y las imágenes que surgen de la performatividad de la palabra.

Los análisis desarrollados en el presente escrito, ponen en cuestión un tipo de escritura que escapa a delimitaciones que convengan en entender y comprender el texto de manera realista; más bien su carácter performativo la acercaría a un tipo de textualidad que permite, dada su estructura, una representación múltiple. Recordemos que la obra parte de forma brusca sin indicaciones de espacio ni tiempo en que esta transcurre, tampoco con características que definan a los cuatro personajes. Más aún, si se hace el ejercicio de cambiar el orden de diversos fragmentos del texto, estos no alterarían la totalidad. La noción de un diálogo tradicional da paso a un gran texto, que puede ser entendido como un monólogo dentro del cual surgen ciertas situaciones dialogizadas que dan luces de un conflicto interno, íntimo y existencial, pero también surge "la renuncia más o menos clara a los "principios de la narración y de figuración", al orden de la fábula así como a la emergencia de una cierta forma de "autonomización del lenguaje" (Cormann, 2015: 256) permitiendo el juego de la palabra en su posible representación, dando cuenta del fin de una ilusión mimética.

La producción de performatividad desplegada por la lectura, es una evidencia clara de cómo las prácticas dramatúrgicas contemporáneas dan cuenta de un deslizamiento o desplazamiento de una textualidad fija a otra más performativa, escapando de los límites establecidos por la lengua. Crave es un tipo de obra que no se cierra en sí misma, dejando abierta una puerta a variadas puestas en escena, acorde a las múltiples imágenes y estados que acciona en el lector/a, a través de un cuerpo/voz que solo puede ser proyectado desde la fragmentación de su existencia, de su historia, de retazos de su memoria, de un pasado que se trae al presente desde cuatro voces que buscan poder sanar su habitar en el mundo. De este modo, la performatividad es producida en la relación que se da con el lector/a como también con el director/a y público. La preponderancia de una dramaturgia performativa no está sólo en la esfera del texto, sino en los intersticios entre este y quien lee; no en la delimitación entre las palabras y su referencialidad, sino en el contagio y la resonancia, en la capacidad de afectar a otro/a, de contagiar y resonar en el cuerpo de otro/a. Una dramaturgia nacida y leída desde la experiencia, en este caso particular, de un lenguaje que es la expresión de una época, desde la propia experiencia al límite de la vida de Sarah Kane. 
AbIRACHed, R. (1994). La crisis del personaje en el teatro moderno. Madrid: Publicaciones de la ADE.

BRncic, C. (2006). "Sarah Kane y el espectáculo del dolor”. Revista Chilena de Literatura, (N. 69). Chile: Universidad de Chile, 25-43.

CARneVAl, D. (2017). La forma dramática y representación del mundo en el teatro europeo contemporáneo. México: Toma, Ediciones y Producciones Escénicas y Cinematográficas: Paso de Gato; Barcelona: Institut del Teatre de la Diputación de Barcelona.

Cormann, E. (2015) “Crisis de la representación. Representación de la crisis. Doce notas para un teatro de crisis". Antología de Teorías Teatrales. Bilbao: Artezblai, 253-279.

Cornago, Ó. (2011) “Introducción En torno al acontecimiento escénico”. Estética de lo performativo. Madrid: Abada Editores, 7-19.

FISCHER-LICHTE, E. (2011). Estética de lo performativo. Madrid: Abada Editores.

Heahtfield, A. (2011). "Dramaturgia sin dramaturgo". Repensar la dramaturgia, Editores: Manuel Bellisco, María José Cifuentes y Ampara Écija. España: Centro Párraga y Centro de documentación y estudios avanzados de arte contemporáneo (CENDEAC), 91-104.

Hormigón, J. (2011) La profesion del dramaturgista. Madrid: Publicaciones de la ADE.

Kane, S. (2005) Crave/ 4.48 Psicosis. Buenos Aires: Ediciones Artes del Sur.

Lehmann, H. (2013). Teatro posdramático. Madrid: CENDAC.

Prieto, A. (2009). "iLucha libre! Actuaciones de teatralidad y performance". Actualidad de las artes escénicas. Perspectiva latinoamericana. México: Universidad Veracruzana, 116-143.

RYNGAERT; Sermon. (2015). “El personaje teatral contemporáneo: descomposición, recomposición”. Antología de Teorías Teatrales. Bilbao: Artezblai, 35-79.

SarrazaC, J. (2011). "Reparto de voces" en Revista Las puertas del drama. Recuperado de http://www.aat.es/pdfs/drama40.pdf

(2013) Léxico del Drama Moderno y Contemporáneo. México: Paso de Gato. (2015) "FORMAS. El reparto de voces". Antología de Teorías Teatrales. Bilbao: Artezblai, 87-91.

TAYLOR, D. (2012). Performance. Buenos Aires: Asunto impreso ediciones. 